\title{
El objeto de estudio como modelo adecuado de aprendizaje
}

The study case as a suit able
learning approach

\author{
Aгq. Mirtha Pallarés T. [ I nvestigador Responsable] / \\ Агq. Marcelo Valenzuela V. [Investigador Alterno] / \\ Aгq. Jing [han Lou [ [olaborador] / \\ Агч. Heгnám Elgueta S. [ [olaborador] /
}

\section{$<$ Resumen>}

Una de las cuestiones más difíciles de resolver en el modelo de enseñanza-aprendizaje de la arquitectura, lo constituye, la integración de las distintas áreas que confluyen a la formación, donde lo habitual, es que se desarrollen en unidades estancas y que por la vía del aporte de cada una de ellas, el estudiante las vuelque en las propuestas que formula. Esto que ha sido la forma estándar de transferencia, se suele apoyar en el descubrimiento de las particularidades para cada ocasión, obviando las que no son relevantes, proceso complejo, ya que los parámetros son cambiantes y no existe claridad acerca de la relevancia de la integración de todas y cada una de las cuestiones que intervienen.

La concepción de la arquitectura como un todo, explicada a través de las distintas miradas que la condicionan, es posible de transmitirse en la medida que se utilicen como objetos de estudio, modelos arquitectónicos que en su concepción, respondan a cada una de las áreas del pensamiento que las motivaron y que explican su materialización.

\section{$<$ Abst ract $>$}

The conception of architecture as a whole is conditioned by the different points of view. These different points of view can be presented as objects of study (architectural models), that are behind each area and that explain its materialization.

<Palabras clave>

APRENDIZAJE INTEGRADO (ARQUITECTURA) / GÓTICO Y NEOGÓTICO / PRODUCCIÓN DEL ESPACIO

$<$ Key words>

NTEGRAL LEARNI NG I N ARCHI TECTURE / GOTHI C AND NEO GOTHI C I SPATI AL PRODUCTI ON
Uno de los desafíos más importantes de la enseñanza de la arquitectura, consiste en promover constantemente la integración de los conocimientos, y para ello, es preciso dotar al estudiante de cualidades analíticas y de capacidad de síntesis, como una condición intelectual necesaria para posicionarse frente al objeto de estudio.

La arquitectura es indudablemente un campo multidisciplinario que compromete diversos aspectos, como las humanidades, ciencias sociales y físicas, la tecnología y las artes creativas, resumidas en tres áreas del conocimiento, como son las humanidades, artes y ciencias; por lo que a la hora de enfrentar la enseñanza de la arquitectura, se desarrolla un proceso que generalmente toma estas áreas por separado, mediante una disociación en la entrega de los conocimientos, y donde cada una de ellas analiza el objeto de estudio de acuerdo con sus especificidades, en circunstancia que debiera tener presente siempre, los puntos de contacto y complementación con las otras áreas. Ello permitiría que el alumno se formara en las particularidades y su interacción con el todo, de manera de poder incorporar en su acerbo 

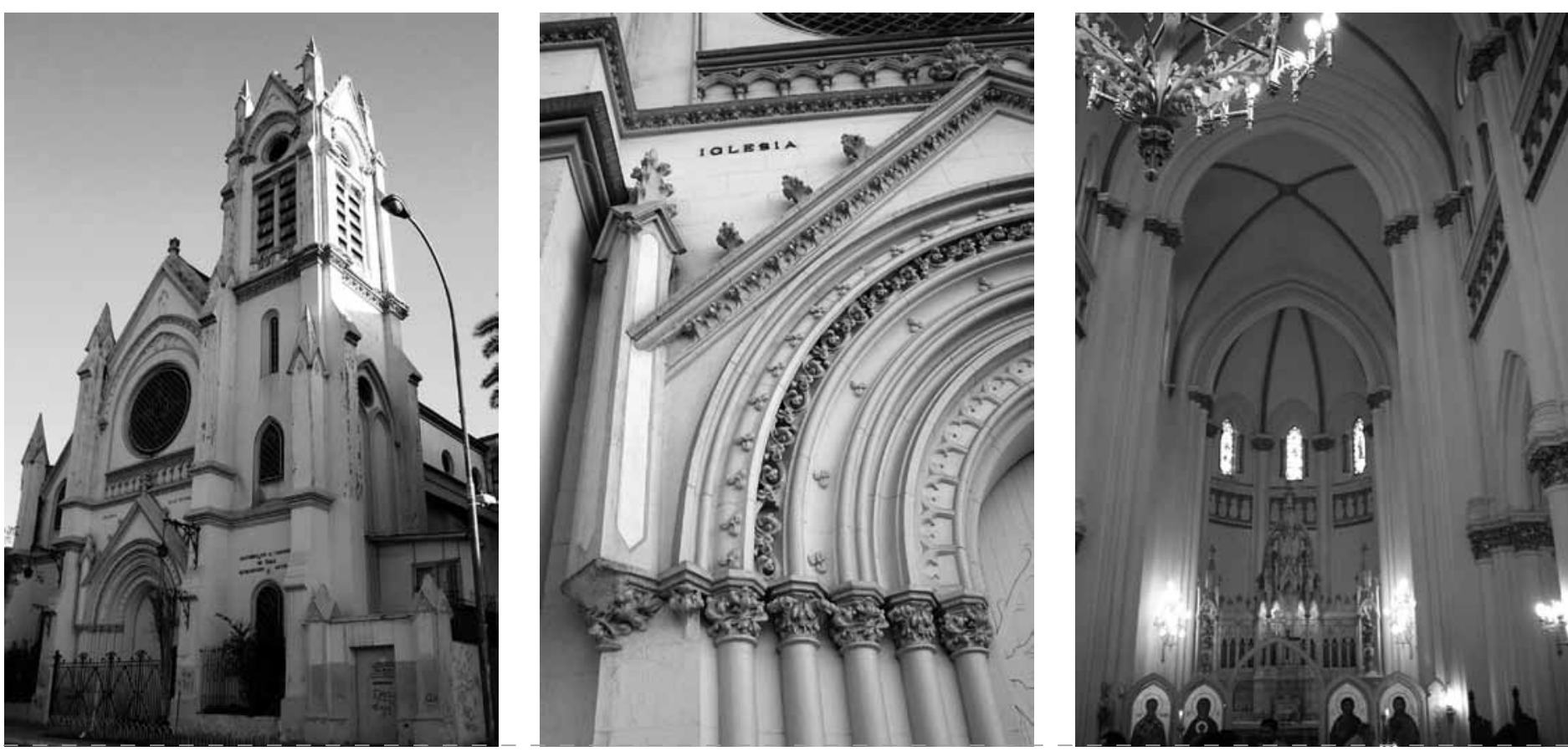

los valores humanos, técnicos y creativos, que le permitan asumir una actitud social de compromiso en las diversas facetas de su vida personal, familiar y profesional.

La integración de todos los conocimientos transmitidos, ya sea para el análisis de un objeto en estudio, o para la entrega de una propuesta, debe otorgar una respuesta que presente un enfoque integrador, que armonice con la formación técnica, estética y ética, a través de un proceso que se manifieste en los diferentes niveles de enseñanza y aprendizaje, que esté de acuerdo con el grado de complejidad de esta, ya sea a través de temas comunes en los distintos niveles o en seminarios de investigación.

Para el arquitecto Roberto Goycoolea Prado ${ }^{1}$, el desafío que conlleva la enseñanza de la arquitectura, nos debiera llevar a reflexionar sobre sus actuales lineamientos, asumiendo una postura crítica frente a los nuevos profesionales que demandarán los nuevos procesos de comprensión, configuración y gestión del espacio.

Considerando que las nuevas técnicas digitales de almacenamiento, tratamiento e intercambio de la información, han cambiado la estructura económica y cultural del planeta, rompiendo fronteras de ciudades y Estados, y generando una nueva forma de integración global, que dan lugar a interrelaciones sociales y mentales nuevas, las que producirán su efecto a la hora de concebir, usar y construir el espacio habitable. "Prever y dar respuesta a estos nuevos requerimientos espaciales, se presenta como la principal tarea de los arquitectos, o de quienes quieran que sean en el futuro los encargados de configurar los espacios reales o virtuales de la sociedad telemática" (Echeverría; 1996).

Luego intuir la orientación que estos cambios generarán, en la manera de entender el mundo por las generaciones venideras, implicará cambios y adecuación en los planes de estudios, orientados a una aproximación antropológica de la enseñanza práctica y teórica de la arquitectura como un proceso cultural, más que como la adquisición de capacidades técnicas.

Para Javier Seguí de la Riva² "las destrezas son formas de hacer, habilidades operativas, que sólo pueden fijarse (en la conciencia) con la ayuda de palabras que describan las operaciones y resultados y

Goycoolea Prado, Roberto. "Arquitectura y Humanidades". Taller de investigación Arquitectura y Humanidades UNAM. México, 1999.

Seguí de la Riva, Javier. Acerca de algunas incongruencias en la enseñanza del dibujo y el proyecto arquitectónico. Madrid: ETSAM, 1998.

den pie a vincular a esos discursos precisas significaciones". Es por ello que opina que "la enseñanza tradicional del proyecto y de sus herramientas debería complementarse con un trabajo teórico mediante el cual el alumno comprenda la relación que existe entre las herramientas utilizadas en la configuración de las formas arquitectónicas y el modo que tenemos de entender el mundo y, con él, la arquitectura. Algo que se podría lograr gravitando el aprendizaje de la arquitectura en la comprensión de los "movimientos generadores" -en el sentido amplio del término- de la forma artística", luego la forma tradicional de la enseñanza de la arquitectura ya no es a través de la transmisión de conocimientos, sino la de conducir al alumno para potencializar la autoformación, mediante la asimilación de contenidos, establecer su relevancia, como su interrelación y puesta en práctica. Conducción dinámica y siempre focalizada hacia una comprensión unitaria y multidisciplinar de la arquitectura.

En este contexto, la investigación "El Origen Geométrico en la Construcción y las Estructuras. Neogótico en Santiago de Chile", financiada por "Fondo de Investigación FAU", nos permitió profundizar los valores tecnológicos, espirituales y sociales del gótico europeo, su transformación al neogótico y su interpretación en Santiago de Chile, temática relevante desde la perspectiva arquitectónica, que permite a través de distintas miradas de estudio, situar las especificidades y comprender el todo. 


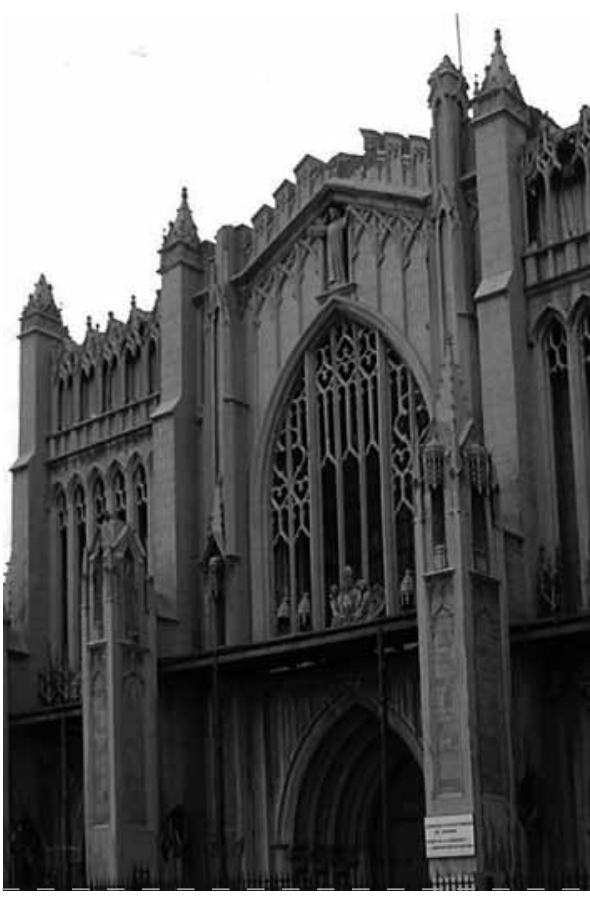

Sabido es que el gótico encontró su gran medio de expresión en la arquitectura, y las mayores realizaciones se manifestaron en el terreno de la arquitectura religiosa en Francia, siendo la Catedral el exponente más completo en cultivar los avances técnicos, introduciendo un lenguaje altamente expresivo y convirtiéndose en el emblema de toda una concepción religiosa, lo que lo transformó en un símbolo de la iglesia cristiana. Las características principales que presenta el gótico responden a un punto crucial de transición histórica, entre la Edad Media dominada por la iglesia y el mundo libre y secular del Renacimiento, lo que constituye la expresión perfecta de la tensión dialéctica entre dos mundos, el de la fe religiosa y el de la razón analítica, y que arquitectónicamente se manifiesta a través de un vocabulario común de formas y contenidos, que nacen de un modelo básico que presenta variaciones locales.

El mundo de la fe se hace ostensible en la arquitectura religiosa, para dotar a las comunidades de un espacio, para desarrollar los aspectos espirituales de la vida, que se manifiesta arquitectónicamente en la verticalidad, altura, esbeltez y luminosidad con que el edificio transmite su sentido de ascensión divina, decisión de carácter simbólico, que responde a una sociedad de religiosidad excepcional, y que generará en la práctica una gran cantidad de desafíos de carácter técnico, a los que se deberá
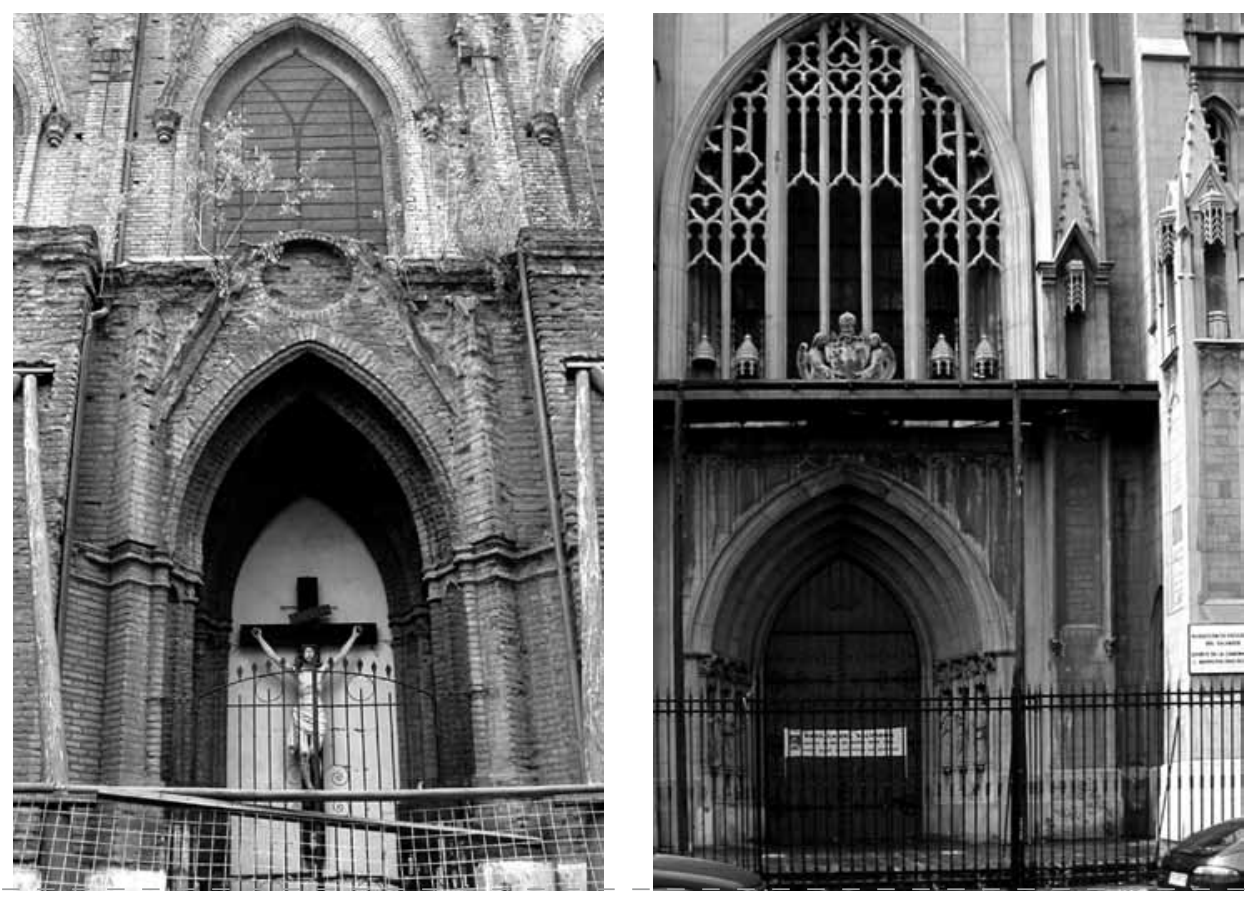

hacer frente aligerando de forma progresiva muros y elementos portantes, en la búsqueda de la menor estructura posible, con el fin de lograr una completa identificación del espacio religioso, con el más espiritual de los elementos, la luz divina, que se manejará tamizada para acentuar la idea de trascendencia, todo ello, con los limitados medios de la época.

Independiente de las limitaciones, la experiencia constructiva acumulada permitió abordar con mayor seguridad y precisión los desafíos, implementando soluciones de mayor riesgo, contribuyendo con ello a acelerar el proceso de evolución de carácter estructural, heredado de la última época Románica. Con lo que se logró perfeccionar el sistema constructivo existente y contribuir a la resolución de problemas de empuje y sobrecargas, al introducir elementos constructivos como el arco apuntado, la bóveda de crucería y el arbotante, cuya íntima fusión permitió el éxito técnico.

Sin embargo, los aspectos de la arquitectura gótica que carecen de precedente son, la utilización de la luz y la nueva relación que se genera entre función y forma, entre estructura y apariencia, que se manifiesta en

la dignidad estética inédita que adquiere la estructura del edificio, junto a una técnica de ejecución perfecta del corte y ensamblaje de la piedra, donde los volúmenes según Otto von Simson $^{3}$ se ven reducidos a líneas, que se nos presentan en precisas configuraciones de figuras geométricas, donde los fustes son las líneas verticales que expresan el principio de sustentación por la dinámica de sus líneas verticales, los nervios son los ángulos en que dos túneles de una bóveda de arista se encuentran, y la bóveda de crucería, un elemento arquitectónico notable, que producto del grafismo geométrico, constituye el verdadero principio de su orden y cohesión estética, medio a través del cual, el arquitecto expresa la imagen de las fuerzas estructurales reunidas en su edificio.

Apreciaciones y enfoques sobre el gótico hay muchos, y ello se debe a que en el transcurso del tiempo, el gótico ha sido objeto de un intenso análisis, que ha buscado descubrir analogías intrínsecas, con fenómenos tan diferente como son las artes, la literatura, la filosofía, los movimientos religiosos, las corrientes sociales y políticas, etc. En este contexto, el profesor Erwin Panofsky, establece una relación de correspondencia entre arquitectura gótica y

von Simson, Otto. La catedral gótica. Los orígenes de la arquitectura gótica y el concepto medieval de orden. Versión española de Fernando Villaverde. Madrid: Editorial Alianza, 1980. 

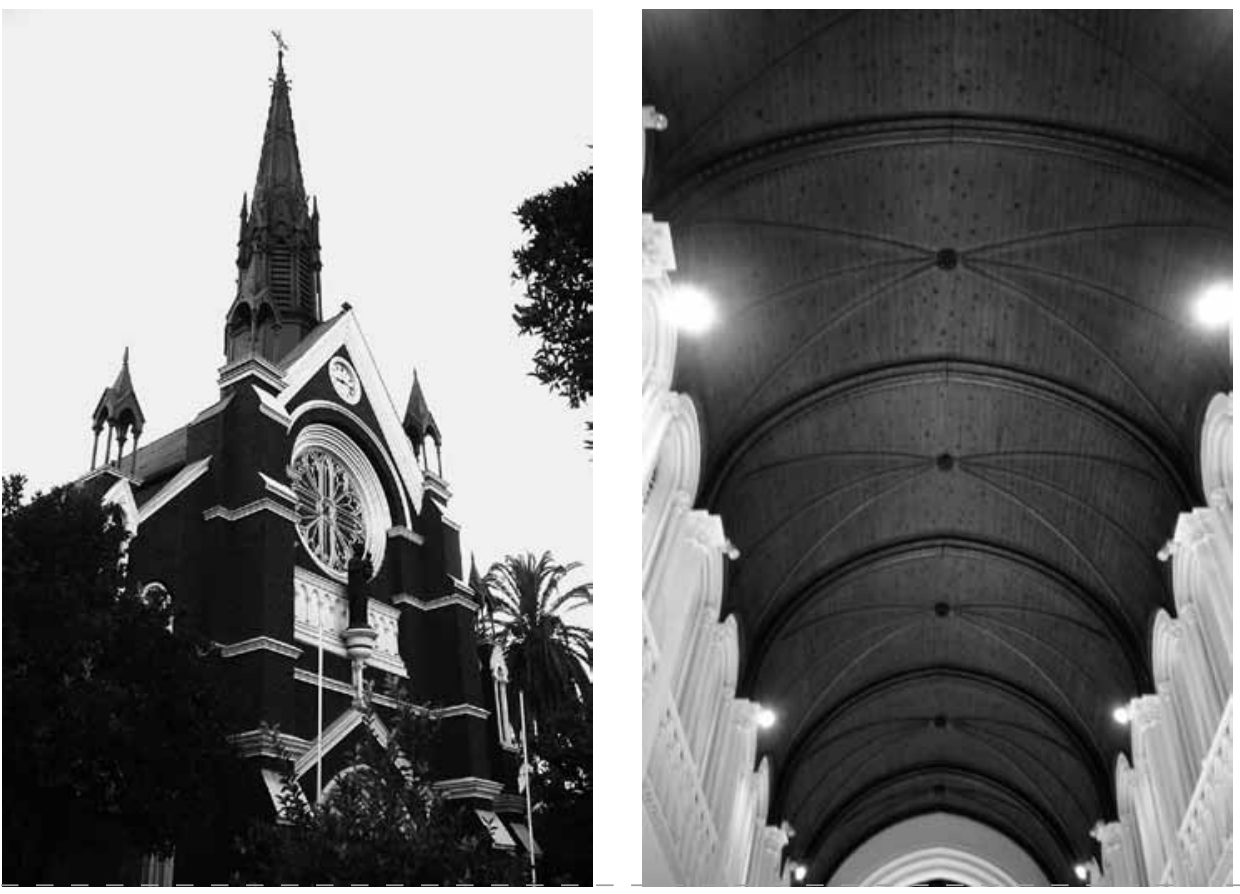

pensamiento escolástico, y que se fundamenta en el tiempo y lugar de gestación en que se desarrolla la arquitectura gótica y el pensamiento escolástico. Correspondencia apreciable para Panofsky, en la visión y desarrollo en que exponen la época, tanto los investigadores de arte, como los historiadores de la filosofía, y que es posible encontrar en las porciones o períodos de análisis de la historia, como son el gótico primitivo, alto gótico y gótico tardío, y sus símil con la escolástica primitiva, alta escolástica y escolástica tardía, todos ellos, períodos que se gestan en paralelo y que se desarrollan bajo patrones comunes.

Sin embargo y si bien, la postura de Panofsky es altamente difundida, y esclarecedora en establecer relaciones internas entre fenómenos disímiles, existen variadas interpretaciones, entre las que quisiera mencionar dos corrientes de opinión, una de ellas dice relación con considerar la arquitectura religiosa gótica como arte, argumento que establece como dice Paul Frankl": "Cuando nos referimos a la peculiar interrelación de forma y significado, en la cual la forma se convierte en el símbolo del significado. En este caso la arquitectura eclesial gótica es arte, porque las formas creadas por artistas góticos interpretan el significado de la civilización de la época”. En esta misma línea para Hans Sedlmayr y Otto von Simson, la Catedral gótica es la integración de todas las técnicas artísticas, cuyo significado reside en la experiencia del edificio como un todo, "la iglesia gótica como un Gesamtkunstwert" ${ }^{5}$. Si bien, esta interpretación no fue compartida por estudiosos de la época, hoy las generaciones actuales de historiadores del arte, aceptan la idea de la iglesia gótica como integración artística, por entregarnos una manera de volver a la catedral originaria con toda su multiplicidad.

La segunda corriente de opinión, plantea un enfoque de análisis distinto al expuesto anteriormente, que se basa en la imagen material que se tiene de la catedral gótica, y que dice relación con el desarrollo neomarxista que se dio en Alemania en la década de 1970, y que se fundamenta en el conocimiento material de las logias y los conflictos sociales de la época. En esta línea de pensamiento, existe una serie de importantes artículos, como los de Dieter Kimpel, que dice relación con el proceso constructivo de la catedral gótica a principios del siglo XIII, donde se produce un cambio en la producción del espacio, lo que altera el aspecto real de los edificios acabados. Para Kimpel, las armazones cada

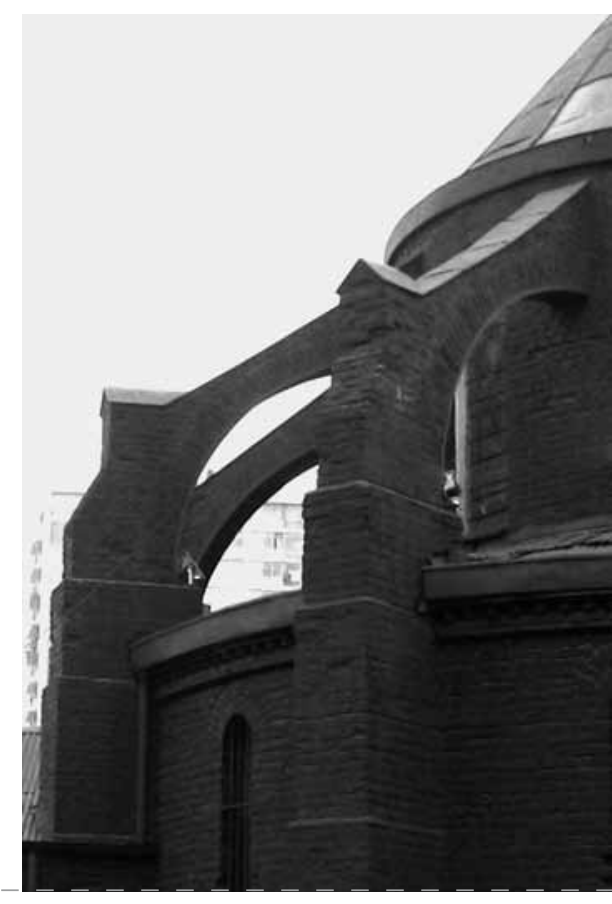

vez más delicadas del gótico francés del siglo XII, procedían no sólo de las preferencias estéticas del arquitecto y del mecenas, sino de nuevas técnicas de producción, las que se relacionan con los nuevos métodos de producción en masa de la piedra extraída en la cantera y cortada en la logia para su posterior almacenamiento, procedimiento que influyó en abaratar y acelerar la construcción, cambiando su aspecto interior. El separar la producción de la instalación de la piedra cortada, su "esqueleto", pilastra, fuste, nervio y arcos, del corte y del ensamblaje de los muros de relleno, hizo que la característica de esqueleto del gótico se convirtiera en un factor que se incorpora a la producción.

Para Henry Lefebvre, el espacio debe ser entendido como producto social, y por ende, las significaciones que genera se relacionan con una determinada estructura social histórica (modo de producción). Por tanto, a un determinado modo de producción histórico le corresponde una forma particular de representación, concepción y percepción del espacio.

Vemos que estas dos corrientes de opinión entregan dos interpretaciones históricas opuestas, una que corresponde a la historia social marxista, que acentúa los conflictos sociales y la autoridad política, con su crítica a la catedral espiritual, que según Kimpel y Suckale entrega un lenguaje sociopolítico, instrumento que inserta al gótico en su medio

$\begin{array}{ll}4 & \text { Frankl, Paul. Arquitectura gótica. 1 }{ }^{\text {ra }} \text { ed. Madrid: Editorial Grupo Anaya S.A., 2002; } 419 . \\ 5 & \text { Ídem. }\end{array}$ 

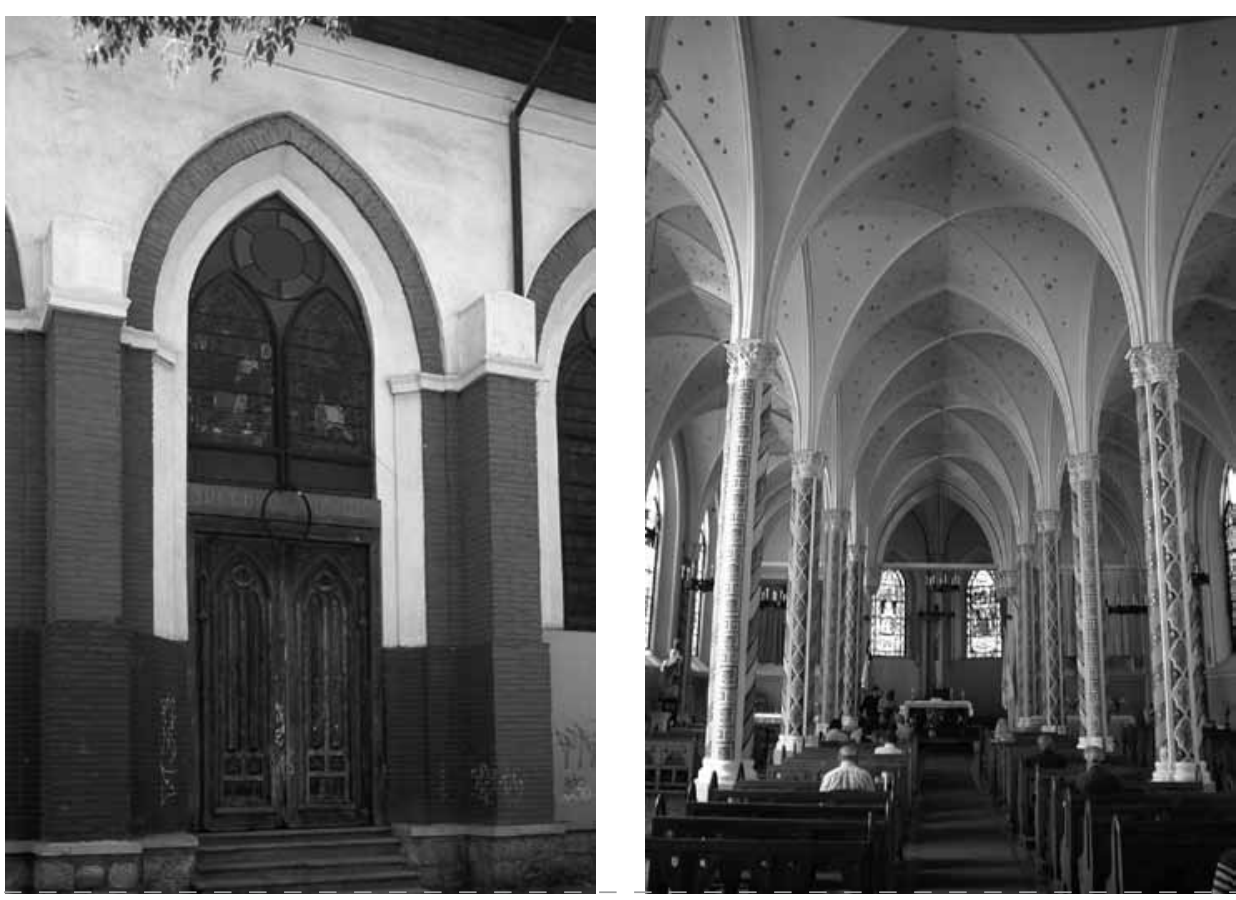

histórico y la otra corriente que ve en el artista el artífice, de la obra arquitectónica.

De la construcción medieval y de sus condiciones especiales de desarrollo, hoy sólo quedan las obras con su enorme poder de sugestión, en cuanto a la búsqueda de datos sobre los fundamentos técnicos que las hicieron posible, el resultado existente es escaso en relación a la cantidad de obras que quieren describir, ya que los escasos documentos, han sido interpretados en exceso para cubrir la realidad de las construcciones.

El desarrollo y caracterización de estos espacios, representarán los valores religiosos y simbólicos de la época, que si bien, presenta diferenciaciones locales en su amplio desarrollo, entrega a través de la arquitectura una forma particular de representación y concepción del espacio, que integra tanto valores espirituales, como técnicos y creativos en un hecho arquitectónico único, que se expande por toda Europa, hasta que en el siglo xIv, cuando se encontraba ampliamente distribuido, cambió hacia una estilo más natural conocido como gótico internacional, que continuó hasta el siglo xv para dar paso a otro estilo denominado renacimiento.

Luego, a mediados del siglo XVIII, se redescubre el gótico a través de un movimiento arquitectónico relacionado con el romanticismo, denominado neogótico, que surge en Gran Bretaña que es donde llega a su máxima expresión. El neogótico es un estilo que evoca y revalora del pasado Medieval y que aparece en Europa, como una contraposición al emergente neoclasicismo nostálgico de tiempos pasados gloriosos de conquistas y poder. El neogótico representa una visión nacionalista y responde a una identidad local relacionada con los valores del humanismo y del liberalismo imperante en la época, que se concreta a mediados del siglo XIX, con motivaciones tanto técnicas como ideológicas.

La posibilidad de usar formas pasadas con un marcado liberalismo, sin ceñirse a los cánones de estilos antiguos, generó seguidores y detractores, siendo descalificado por artificioso y arbitrario en 1846 por la Academia Francesa, sin embargo, fue respaldado por el principal impulsor y defensor del gótico, el arquitecto francés Viollet Le Duc, quién señala en su tratado Entretiens (1863) el potencial emocional del espacio gótico, lo que explica su defensa por ese patrimonio del pasado y su reelaboración inspiradora en el estilo, usando las posibilidades de un material industrial propio de su generación: el hierro, para proponer una "nueva arquitectura de construcción nacional". Sus escritos, sus obras de restauración del patrimonio gótico francés, sumados a sus nuevas propuestas arquitectónico-estructurales-constructivas lo hacen el estudioso más afamado del gótico. Sin embargo su trabajo literario de mayor interés sobre este contenido es su enciclopédico "Diccionario", donde expone

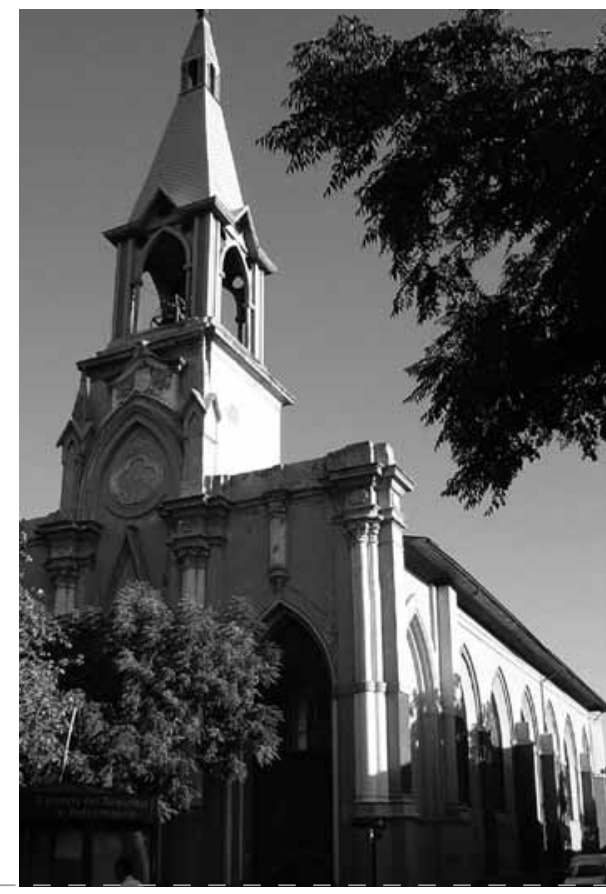

y desarrolla bajo el concepto "construcción" el sistema constructivo gótico a través de innumerables dibujos ampliamente difundidos, donde muestra la claridad del sistema a través de la economía de sus soluciones.

Un siglo más tarde llega el neogótico a Chile, cuando el país ya gozaba de su independencia, época republicana que permitió abrirse a todo intercambio económico y cultural con el mundo y Europa, que sumado al auge económico, producto del extraordinario desarrollo de la economía minera de plata, oro y carbón, trajo consigo la emigración de familias de provincias o del extranjero a la capital con influencias externa, como también se dio, que al tener más recursos fue posible salir fuera del país y al volver materializar lo visto, generando un cambio de costumbres, trasformándose en una sociedad pujante, ávida de asimilar los modelos Europeos de la época.

El neogótico que se da en Chile a mediados del siglo xIx toma la arquitectura europea y la adapta a las técnicas constructivas locales, manteniendo un estilo más bien ecléctico. En la primera mitad del siglo $x x$ se construye la mayoría de las iglesias neogóticas, transformándose más bien en una arquitectura de proporciones modestas con gran apego a cánones formales del gótico medieval, y donde cada una de ellas es un aporte significativo para el tiempo en que fue gestada pero con una significación simbólica 

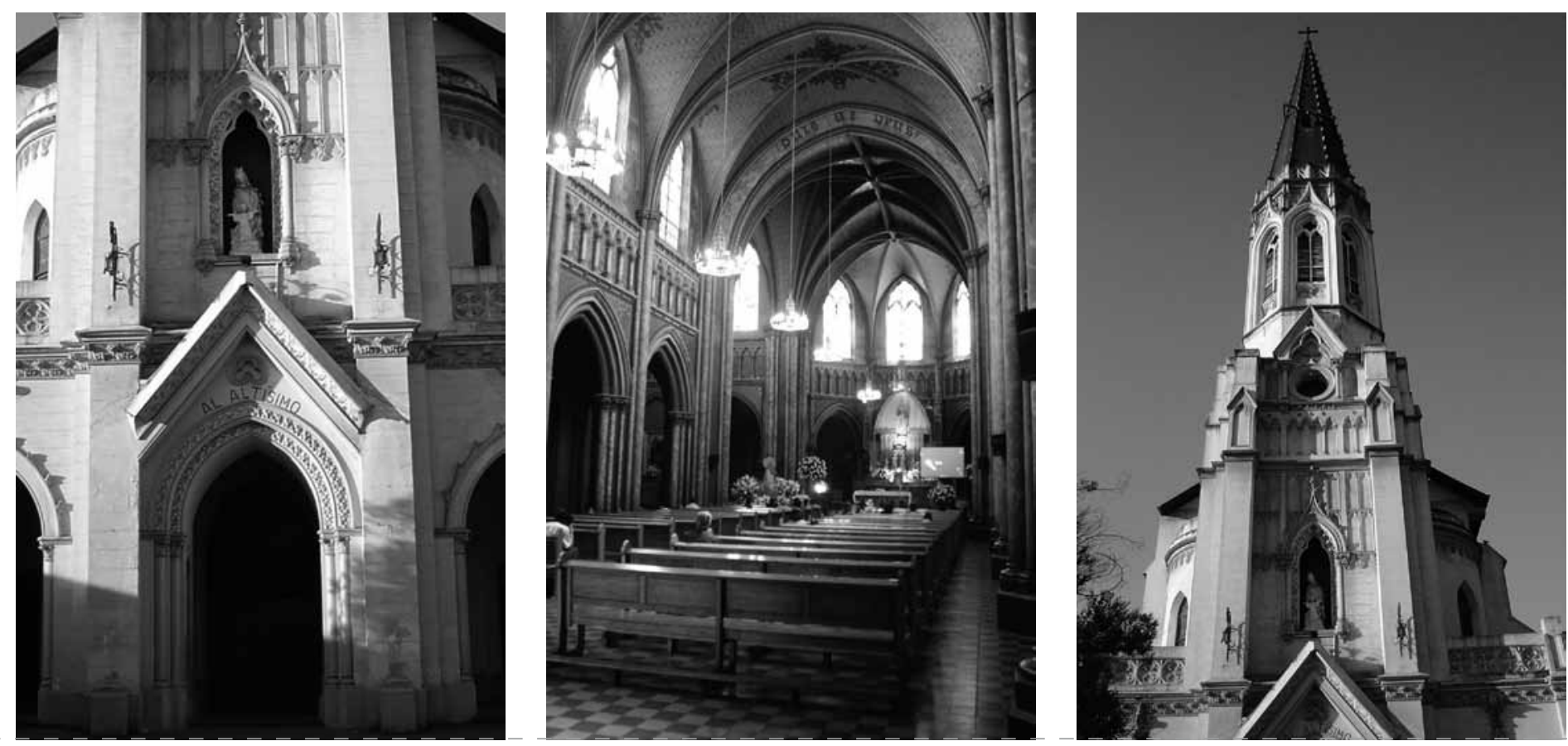

que es extemporánea y representa más bien, un código de lectura compleja y variada.

De las iglesias catastradas en la capital que presentan el estilo neogótico podemos observar una etapa inicial que insinúa el estilo, una segunda etapa con características formales, estructurales y espaciales,

comparables con las del estilo originario y una tercera etapa que se diferencia de la anterior, por la incorporación de nuevos materiales, como son las estructuras metálicas y el hormigón armado. En todo caso independiente de cual de ellas incorpore más características del estilo, todas forman parte de nuestro patrimonio arquitectónico y son comparables con el estilo originario por representar un determinado modo de producción del espacio y su mayor diferencia radica en la materialidad, es decir en las distintas técnicas de producción del espacio.

La arquitectura religiosa gótica y su reinterpretación a través del neogótico en Santiago de Chile: Elementos que la relacionan

Si bien las primeras iglesias góticas adoptaron una gran variedad de formas, mantuvieron y perfeccionaron su concepción espacial, basada en una composición similar a la de la arquitectura Románica, con elementos como la girola, espacio de forma semicircular que aparece en la cabecera de templo, el deambulatorio donde convergen capillas radiales de planta semicircular o poligonal, como también la organización de los alzados en el interior de las naves y en el coro. Todo ello en una nueva concepción que busca la verticalidad y la luz, mediante esbeltos pilares que separan las naves, y que están compuestos por finos fustes que suben a través del triforio hasta las nervaduras de las bóvedas de crucería, y del uso del arco apuntado. En la bóveda de crucería se concentran los empujes en puntos determinados los que posteriormente descienden por pilares, columnas o arbotantes, logrando cerramientos ligeros, alturas insospechadas y formas variadas.

Las características básicas de esta nueva concepción se pueden apreciar en el desarrollo y distribución de los espacios que conforman el edificio y que es posible valorar a través de los elementos que lo hacen reconocible, al recorrer sus plantas y alzados con los elementos y espacios que los componen. Una nave central que es simétrica con respecto al eje longitudinal, está delimitada por una sucesión de arcadas, elementos generadores de todos los límites espaciales góticos y que relacionan las naves laterales. A partir de las arcadas nacen los fustes que rematan en las bóvedas de la nave central, estableciendo la organización de la bóveda nervada y proporcionando los elementos horizontales del muro gótico; galería, triforio y claristorio, que transforma el muro macizo románico quedando sólo su esqueleto.

La modulación que presenta la planta, corresponde al módulo de crucería empleado para la cubierta, el que se mantiene con la evolución del gótico, donde si bien, el desarrollo del programa cambia, nunca se pierde la sensación de que se trata del mismo edificio. La fachada típica gótica está articulada en tres niveles o cuerpos horizontales y tres secciones verticales que se corresponden con las naves del interior. Las dos torres cuadradas laterales que se rematan generalmente con agujas o capiteles, forman parte de la fachada con forma de $\mathrm{H}$ y finalmente un rosetón en el centro que tiene una función simbólica. Su decoración es de carácter vegetal y las puertas de acceso suelen coincidir con el número de naves y están formadas por grandes pórticos que por lo general tienen en sus jambas las esculturas de los apóstoles. Otro elemento característico son los pináculos, que los encontramos en los contrafuertes, las flechas de las torres y la aguja que se encuentra entre ellas.

\section{El aporte del gótico a la} enseñanza de la arquitectura

El principal atractivo de una forma o estilo de la arquitectura, definitivamente no está exclusivamente en su significación, sino 

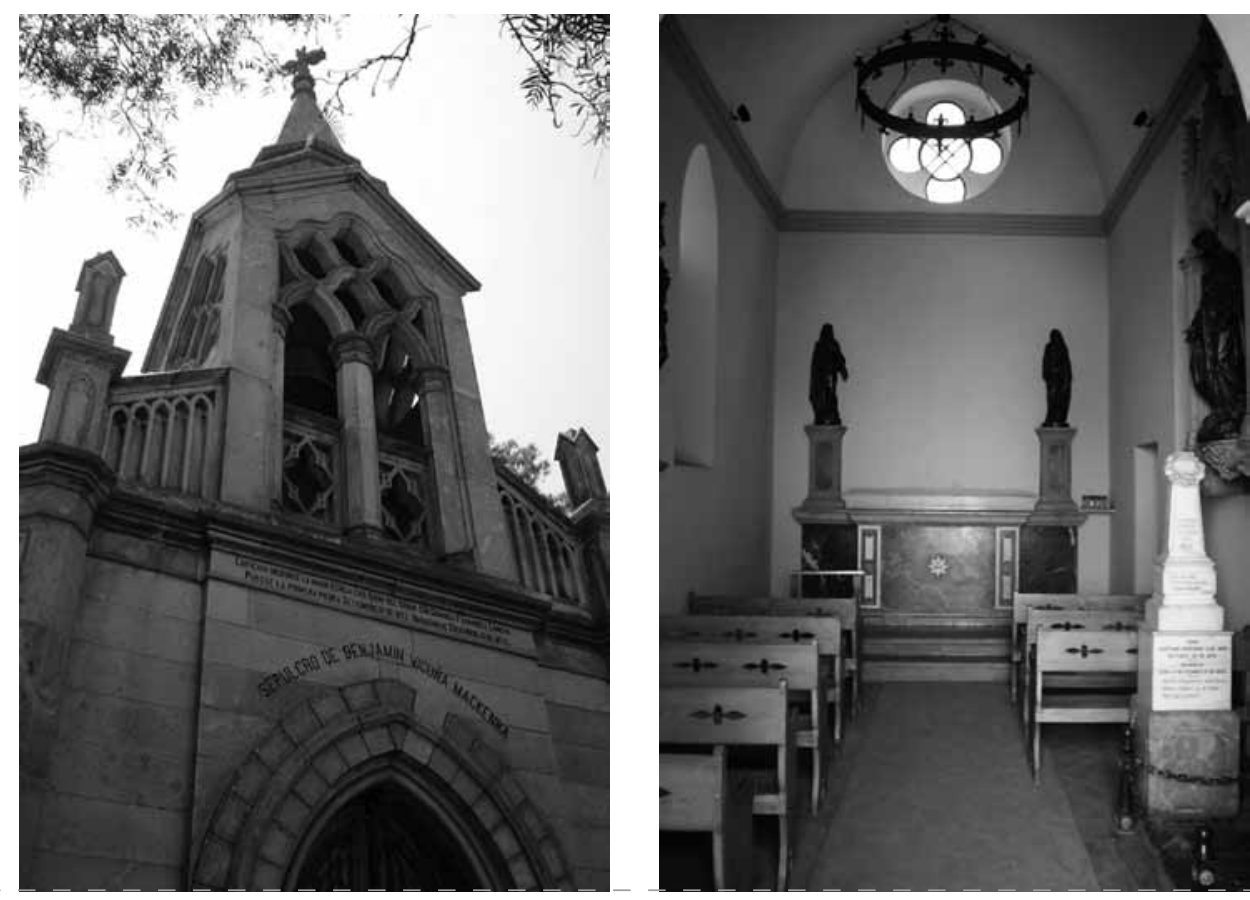

que metodológicamente en la trascendencia que adquiere el modelo que lo fundamenta, el cual es posible transmitir como ejemplo de consecuencia en su desarrollo, en la medida que incluya desde su concepción hasta su materialización física, las variables que condicionan el proceso arquitectónico. En este contexto, el gótico es mucho más que un estilo y la expresión de una época, es definitivamente la manera como se convierte en arquitectura la expresión del pensamiento de una época, con la acción, la materialización y la permanencia en el tiempo.

El gótico es la expresión de una época y de una lugaridad, surge en la Europa de cambio, aquella que muta desde la escolástica medieval a una visión cristiana de la

religiosidad centrada en los valores propios del hombre, esa que reconoce al hombre como fin de la creación y lo proyecta a través del arte como su medio de expresión.

Si intentamos encontrar el hilo conductor que fundamenta las acciones del gótico en su desarrollo y puesta en valor, nos encontramos que es la geometría la ciencia que origina, conduce, regula y simboliza, el desarrollo de la arquitectura gótica, la que se expresa en el diseño del trazado que considera el orden básico de los elementos geométricos y sus relaciones, los que se transforman en artífices señeros del diseño, al reconocer las proporciones y la simbología que conllevan consecuentes con el pensamiento de la época y que entonces era la lógica y la razón que fundamentaba la presencia del ser humano, cuestión que hoy es la tecnología y los sistemas de producción del espacio.

La materialización expresada a través de un sistema constructivo propio, que considera el material como elemento básico y a sus leyes como patrón de acción, permite que las intervenciones representen leyes propias de su naturaleza; en este contexto, la estereometría de la piedra constituye la razón que fundamenta las diferentes propuestas, y la estructura social de las cofradías de constructores. Es así como el tallado pasa a ser no sólo la forma como las partes conforman el todo, donde la sumatoria de ellas adecuadamente colocadas permiten dar forma al edificio, como también conforman la organización social de una época.

Estructuralmente se entiende como un modelo que permanece, luego es fundamental reconocer las variables del diseño estructural que lo permitan, de allí que la transmisión de cargas en un modelo estático acoge la gravedad como parámetro, y en ese escenario organiza las partes como transmisoras y conductoras, de manera que siempre repartan su peso propio y trasladen al receptor la conducción de la acción. La esbeltez que se percibe, no es otra cosa que la adecuada transferencia de cargas, donde lo que prevalece es esencialmente la conducción.

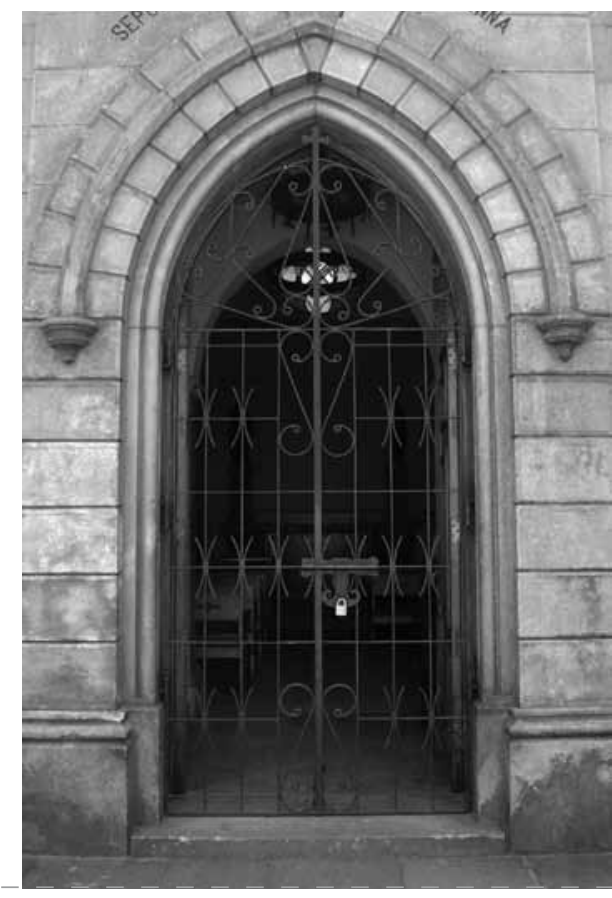

El análisis de la arquitectura gótica es sin lugar a dudas hasta nuestros días, el mejor modelo de interpretación integral de la arquitectura y los valores y parámetros que la condicionan.

\section{Bibliografía}

Cariola, C. Un siglo de historia económica en Chile 1830-1930. Santiago, Chile: Editorial Universitaria, 1991.

Castro Villalba, Antonio. Historia de la construcción medieval y sus aportaciones. Barcelona: Ediciones UPC, 1996.

Coxeter, H.S.M. Fundamentos de geometría. $1^{\text {ra }}$ ed. México: Limusa-Wiley, 1971.

Dirección de Obras Municipales de Santiago. Santiago Poniente, Desarrollo Urbano y Patrimonio. Santiago, Chile: Ilustre Municipalidad de Santiago, 2000

Echeverría, Javier. "Periodismo electrónico en la sociedad del futuro". Conferencia en Colegio de Periodistas. Barcelona, 22/3/1996.

Departamento de Diseño Arquitectónico, Facultad de Arquitectura y Urbanismo, Universidad de Chile. Guía de la arquitectura de Santiago. Santiago, Chile: Ediciones Facultad de Arquitectura y Urbanismo, 1985.

Ministerio de Vivienda y Urbanismo con la consultoría del Departamento de Historia y Teoría de la Arquitectura de la Facultad de Arquitectura y Urbanismo de la Universidad de Chile. Estudio Catastro 

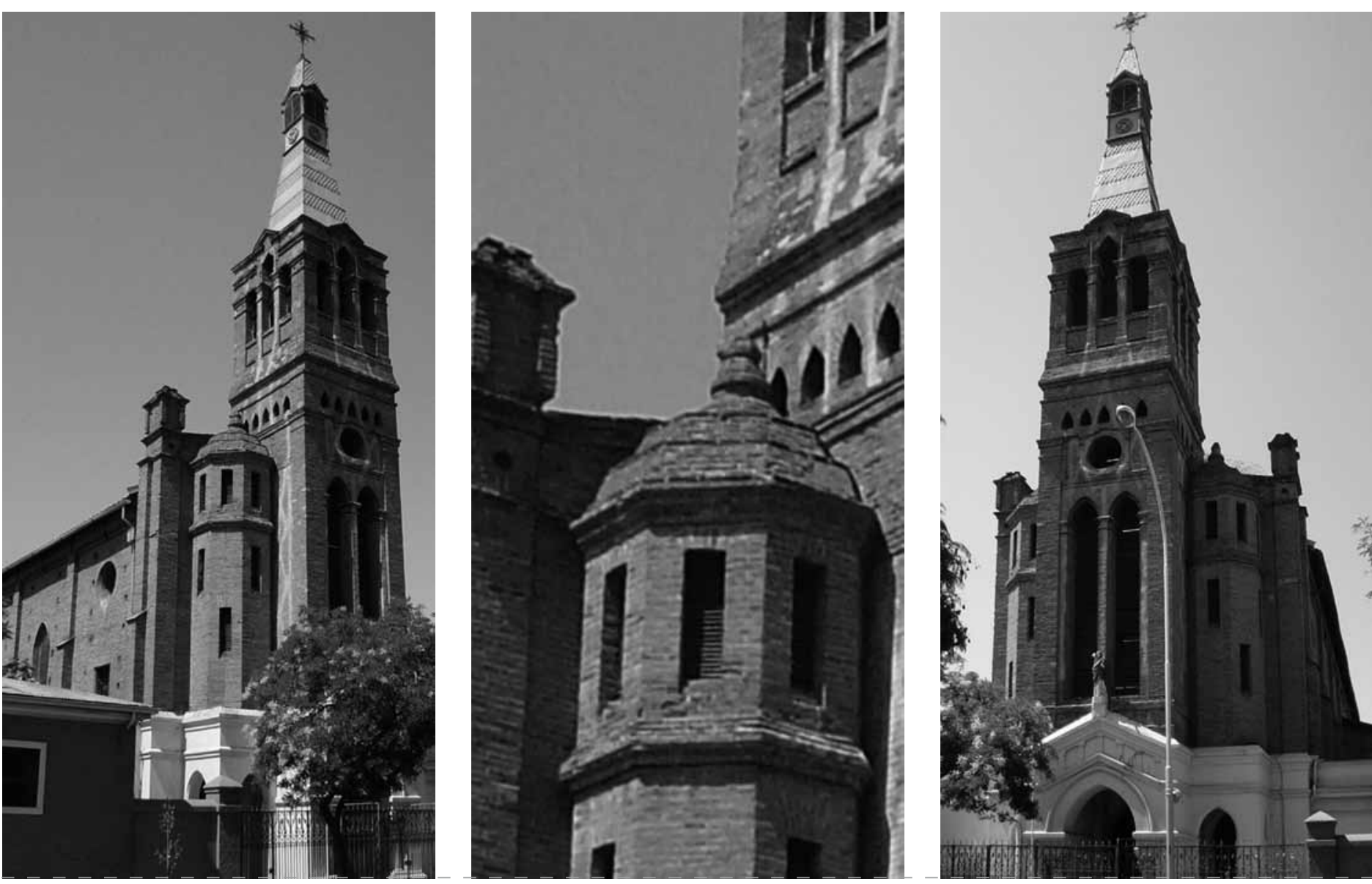

Patrimonio Arquitectónico Inter-Comuna de Santiago e Instrumentos que Promuevan su Conservación. Santiago, 1989-1991.

Frankl, Paul. Arquitectura gótica. Madrid: Ediciones Cátedra (Grupo Anaya S.A.), 2002.

Ghyka, M. Estética de las proporciones en la naturaleza y en las artes. Barcelona: Editorial Poseidón, 1983.

Herman, Jacques. Estructuras de fábrica. Madrid Instituto Juan de Herrera, Escuela técnica Superior de Arquitectura, 1995.

Gombrich, E.H. El sentido del orden. Barcelona: Editorial Gustavo Gilli, 1980

Lefebvre, Henri. La producción del espacio. París, 1974

Panofsky, E. Arquitectura gótica y pensamiento escolástico. Madrid: Ediciones de la piqueta, 1986

Gutiérrez, L.; Tomicic, R. "Iglesias neogóticas de Santiago". Seminario Facultad de

Arquitectura y Urbanismo. Universidad de Chile, Profesor Silvia Pivotte, Santiago, 1979.

Pedoe, D. La geometría en el arte. Barcelona: Editorial Gustavo Gilli, 1979.

Seguí de la Riva, Javier. Acerca de algunas incongruencias en la enseñanza del dibujo y el proyecto arquitectónico. Madrid: Escuela Técnica Superior de Arquitectura, 1998

Von Simson, Otto. La catedral gótica: Los orígenes de la arquitectura gótica y el concepto

medieval de orden. Versión española de Fernando Villaverde. Madrid: Editorial Alianza, 1980.

Villalobos, Sergio et al. Historia de Chile. Santiago, Chile: Editorial Universitaria, 1982

Viollet-Le-Duc, E. Divagaciones sobre arquitectura. París, 1872

Viollet-Le-Duc, E. Diccionario de arquitectura. París, 1858-1868.

Viollet-Le-Duc, E. La construcción medieval. Madrid: Instituto Juan de Herrera, Escuela técnica Superior de Arquitectura, 1996. 